\title{
Micromorfología de los foliolos de pejibaye Bactris gasipaes (Arecaceae) var. Diamantes-10
}

\author{
Ethel Sánchez Chacón ${ }^{1,2}$, Olman Alvarado Rodríguez ${ }^{1}$, Alexander Rodríguez Arrieta ${ }^{1,2,3}$ \& \\ Luis Gómez Alpízar ${ }^{4,5}$ \\ 1. Centro de Investigación en Estructuras Microscópicas, Ciudad de la Investigación, Universidad de Costa Rica, San \\ Pedro de Montes de Oca, San José, Costa Rica, Apartado 2060; old7806@gmail.com \\ 2. Escuela de Biología, Facultad de Ciencias, Universidad de Costa Rica, San Pedro de Montes de Oca, San José, Costa \\ Rica; ethel.sanchez@ucr.ac.cr \\ 3. Escuela de Ciencias Agrarias, Universidad Nacional de Costa Rica, Heredia, Costa Rica; \\ jesus.rodriguez.arrieta@una.cr \\ 4. Centro de Investigaciones Agronómicas, Ciudad de la Investigación, Universidad de Costa Rica, San Pedro de Montes \\ de Oca, San José, Costa Rica, Apartado 2060. \\ 5. Facultad de Ciencias Agroalimentarias, Universidad de Costa Rica, San Pedro de Montes de Oca, San José, Costa \\ Rica, Apartado 2060; luis.gomezalpizar@ucr.ac.cr
}

Recibido 27-VII-2015. Corregido 12-II-2016. Aceptado 08-III-2016.

\begin{abstract}
Micromorphology of pejibaye leaflets Bactris gasipaes (Arecaceae) var. diamonds-10. Bactris gasipaes is widely cultivated for the consumption of palm hearts and fruits. The present work describes the micro morphological characteristics of leaflets from adult plants of B. gasipaes, thornless variety Diamantes-10, collected in the Diamantes Experimental Station in Guápiles, Costa Rica. We collected 25 leaflets and analyses were performed with a combination of microscopy techniques: light microscopy, scanning electron microscopy and transmission electron microscopy to study their structure. Our results showed that leaflets have abundant epicuticular wax on adaxial and abaxial surfaces. Analyses from the epidermis indicated that it is composed of isodiametric cells, and it is also evident that hypodermis cells have rectangular shape and are larger than the other epidermal cells. We observed stomata on both surfaces, but they were more abundant in the abaxial surface. On the other hand, the epidermis showed the presence of trichomes with three different morphologies. In the parenchyma, cells are large and not well defined, and we observed the presence of astroesclereids, and compact groups of fiber bundles between parenchyma cells. The central vein has several vascular bundles, arranged in a continuous manner, and they are surrounded by sclerotic tissue; some of these fibers presented live protoplasts. All minor veins showed the same anatomy as the central vein. In these veins, the vessel elements of protoxylem and metaxylem showed scalariform ornaments on their walls. Phloem is located towards the adaxial surface of the vein and we observed sieve and companion cells surrounded by fibers and parenchyma cells. The companion cells presented branched plasmodesmata attached to a sieve element, and in these elements we found protein bodies called P-protein. The main anatomical difference in the leaflets of the var. Diamantes-10, compared to the other varieties of $B$. gasipaes $\mathrm{K}$, is the lack of thorns; the other morphological features seem to be conserved. Rev. Biol. Trop. 64 (3): 1273-1285. Epub 2016 September 01.
\end{abstract}

Key words: ultrastructure, leaflets, var. Diamantes-10, palm hearts, peach palm.

En Costa Rica Bactris gasipaes es comúnmente llamado pejibaye, pero en otros países se le conoce como chontaduro, pibá, pupunha, peach palm y pijuayo. Se cultiva desde México hasta Bolivia, incluso en Matto Grosso y Sao Paulo en Brasil (Mora-Urpí \& Gainza, 1999). El aprovechamiento del pejibaye es muy antiguo y constituye la palmera de mayor importancia en América desde tiempos precolombinos (MoraUrpí, Weber \& Clement, 1997).

Varias autores han estudiado las palmas intensamente, tanto en aspectos anatómicos 
como ecológicos y se han realizado estudios morfológicos e histogenéticos de especies de palmas como: Bactris gasipaes, Borassus sp., Caryota sp., Cocos sp., Phoenix sp. y Rhapis sp. (Kaplan, 1982 a, b (citado por Tomlinson, 1990); Clement \& Mora-Urpí, 1982; Clement, Mora-Urpí, \& Costa., 1985; Ferreira, 1999; Horn, Fisher, Tomlinson, Lewis, \& Laubengayer, 2009; Tomlinson, 1990, Tomlinson, Horn, \& Fisher, 2011; Valera, Maciel, Sanabria-Chópite, \& Mendoza, 2012; Magellan, Tomlinson, \& Huggett, 2015). Respecto a B. gasipaes, se ha estudiado la ecología de la especie debido a que se utiliza el fruto y la médula como producto alimenticio y la madera también es aprovechada para diferentes usos (Mora-Urpí et al., 1997; Chaimsohn, Montiel, Villalobos, \& Mora-Urpí, 2008). No obstante, a la fecha, son pocos los estudios ultraestructurales que existen sobre la anatomía de B. gasipaes (Batagin-Piotto et al., 2012), y sobre la variedad Diamantes-10 no existe ningún estudio al respecto.

Morfológicamente se describen siete secciones importantes en la estructura de la planta del pejibaye: la corona, la inflorescencia, las flores, los racimos, los frutos y las semillas (Mattos-Silva, 1992; Mora-Urpí, 1993). La corona puede estar formada por 10 a 30 hojas pinnadas. No existe una separación clara entre el pecíolo y la vaina. La vaina y el pecíolo juntos pueden llegar a medir $107 \mathrm{~cm}$ de longitud, mientras que las hojas pueden medir entre 178 y $390 \mathrm{~cm}$ de longitud, y tienen entre 180 a 380 foliolos que son siempre bífidos y por lo general pubescentes (Mora-Urpí \& Gainza, 1999).

En su estructura externa, cada foliolo presenta venas paralelas a la vena central. Al microscopio electrónico, se observan cubiertas de células rectangulares largas, las células de la epidermis tienen forma ondulada y los estomas están rodeados por tres células; el foliolo es anfiestomático, aunque la superficie abaxial presenta mayor número de estomas (BataginPiotto et al., 2012). Ambas superficies presentan varios tipos de tricomas (Chaimsohn et al., 2008; Horn et al., 2009; Tomlinson et al., 2011, Batagin-Piotto et al., 2012).
Respecto a la variedad Diamantes-10, ésta se caracteriza por la ausencia de espinas en la base de la vaina, y por la presencia de muy pocas en la base de la vena central y la superficie del foliolo; esta ausencia general de espinas, la convierte en un cultivo de fácil manejo en el campo (Mora-Urpí \& Gainza, 1999). Las anteriores características se asocian con un mejor manejo agronómico y favorecen la industrialización de esta planta (Arroyo \& Mora-Urpí, 2002).

Esta variedad es muy robusta al transcurrir un año de cultivada y su producción es abundante; además presenta un rápido crecimiento y la vaina de la hoja guía es de mayor tamaño que en variedades como Utilis-Tucurrique y Diamantes-1 (Arroyo \& Mora-Urpí, 2002). En el estudio realizado por Arroyo \& MoraUrpí (2002), se encontró que la producción de palmito de la variedad Diamantes-10 es significativamente superior a otras variedades cultivadas en Costa Rica, y que por unidad de área, la producción puede ser mucho mayor (Bogantes, Agüero, \& Mora-Urpí, 2004). El palmito de pejibaye constituye un importante producto de exportación, y un alimento "gourmet", que genera un buen porcentaje de divisas para Costa Rica (Mora-Urpí \& Gainza, 1999).

Actualmente, existen pocos estudios sobre la microanatomía de $B$. gasipaes, sin embargo, éstos han sido realizados en otras variedades (Parthasarathy \& Tomlinson, 1967; Parthasarathy, 1968; Pérez \& Rebollar, 2003; Passos \& Mendonca, 2006; Horn et al., 2009; Tomlinson et al., 2011; Valera et al., 2012). Al no haber reportes sobre aspectos micromorfológicos para esta variedad, el objetivo de este estudio fue describir con detalle las características micromorfológicas de los tejidos normales de los foliolos de plantas de B. gasipaes var. Diamantes-10. Esta investigación, además de brindar nueva información, resulta básica para futuros estudios sobre anatomía, fisiología y ecología de este importante cultivo.

\section{MATERIALES Y MÉTODOS}

Las muestras de foliolos de B. gasipaes var. Diamantes-10 se obtuvieron en la Estación 
Experimental Diamantes del Ministerio de Agricultura y Ganadería (MAG), ubicada en Guápiles, Pococí, Limón, en marzo del 2014. La estación se encuentra a $249 \mathrm{msnm}$ y presenta una temperatura máxima de $28^{\circ} \mathrm{C}$ y una mínima de $22{ }^{\circ} \mathrm{C}$, la humedad relativa es de aproximadamente $91 \%$ (Mora-Urpí, ArroyoOquendo, Mexzón-Vargas, \& Bogantes-Arias, 2008). Se recolectaron muestras de 25 foliolos de hojas número 2 de plantas de tres años de edad. Los ejemplares se cortaron utilizando un bisturí, se obtuvieron secciones de vena central, venas laterales y fragmentos de lámina foliar. Las muestras se recolectaron de la parte basal, media y distal de los foliolos.

Microscopía de luz: Secciones de foliolos de aproximadamente $0.5 \mathrm{~cm}^{2}$ fueron fijadas por 48 horas en solución Karnovsky. Se utilizó una metodología de procesamiento descrita anteriormente (Chaimsohn, Montiel, Villalobos, \& Mora-Urpí, 2008). Los cortes fueron observados con un microscopio óptico compuesto (Olympus, modelo DP71) y las fotografías fueron tomadas con cámara digital (Olympus, modelo $\mathrm{N}^{\mathrm{o}}$ D-535 Zoom).

Sin embargo, se utilizaron pocas micrografías de luz, pues posiblemente por la gran cantidad de fibras que los foliolos presentaron, hubo poca infiltración de la parafina en las muestras. Por lo tanto, se decidió dar mayor énfasis a los estudios con microscopía electrónica.

\section{Microscopía Electrónica de Barrido} (MEB): Las diferentes secciones de hoja de aproximadamente $1.0-1.5 \mathrm{~cm}^{2}$ se fijaron en solución fijadora de Karnosvky (Karnovsky, 1965) para posteriormente procesarlas según la técnica de Robards \& Wilson (1993). Las muestras secas se montaron sobre bases de aluminio utilizando cinta adhesiva de carbón doble cara (Double Sided Carbon Tape, Cat. N ${ }^{\circ}$ 77817-50. Elecctron Microscopy Sciences) y se cubrieron con una capa de aproximadamente $60 \mathrm{~nm}$ de oro, empleando un cobertor iónico (Eiko 1B-3, Japón). Éstas se observaron con un microscopio electrónico de barrido (MEB)
Hitachi S-570. Para la toma de micrografías, se utilizó una cámara digital (Pentax K-100).

Criofractura: Se tomaron secciones de cada tipo de muestra con un tamaño de $1.5 \mathrm{~cm}^{2}$, se fijaron en solución Karnosvky (Karnovsky, 1965) por aproximadamente $24 \mathrm{~h}$; posteriormente, se realizó el procesamiento según Bozzola \& Russell (1992). Al montar la muestra, la cara obtenida con el corte se orientó para observarla con el MEB Hitachi S-570.

\section{Microscopia Electrónica de Transmisión} (MET): Las diferentes muestras de aproximadamente tres $\mathrm{mm}^{2}$ se fijaron en solución de Karnosvky (Karnovsky, 1965) por aproximadamente $12 \mathrm{~h}$, y luego se procesaron según la metodología de Robards \& Wilson (1993).

Los cortes ultrafinos (entre 70 y $90 \mathrm{~nm}$ de grosor) se realizaron utilizando un ultramicrótomo (Power Tome PC, PMC Products by Bockeler®) y una cuchilla de diamante (Diatome MT2870, Ultra $35^{\circ}, 2 \mathrm{~mm}$, Suiza), luego se contrastaron con acetato de uranilo acuoso al $4 \%$ e hidróxido de plomo (solución saturada), y se observaron al microscopio electrónico de transmisión (MET) H-7100 (Hitachi), con un voltaje de aceleración de 100000 voltios.

\section{RESULTADOS}

Las hojas de B. gasipaes analizadas son pinnadas con aproximadamente 160 foliolos (80 a cada lado) (Fig. 1A), son pubescentes en la ambas superficies (adaxial y abaxial) observándose en mayor cantidad en la superficie abaxial (Fig. 1B). El color es verde oscuro en la superficie adaxial y verde más claro en la superficie abaxial. Cada foliolo tiene varias venas laterales (paralelas) y una vena central más prominente, que tiene una mayor curvatura en la superficie adaxial (Fig. 1A).

La epidermis está compuesta por células isodiamétricas (Fig. 1C, Fig. 1D y Fig. 2A) y la presencia de una hipodermis constituida por células de mayor tamaño de forma rectangular (Fig. 2A). 

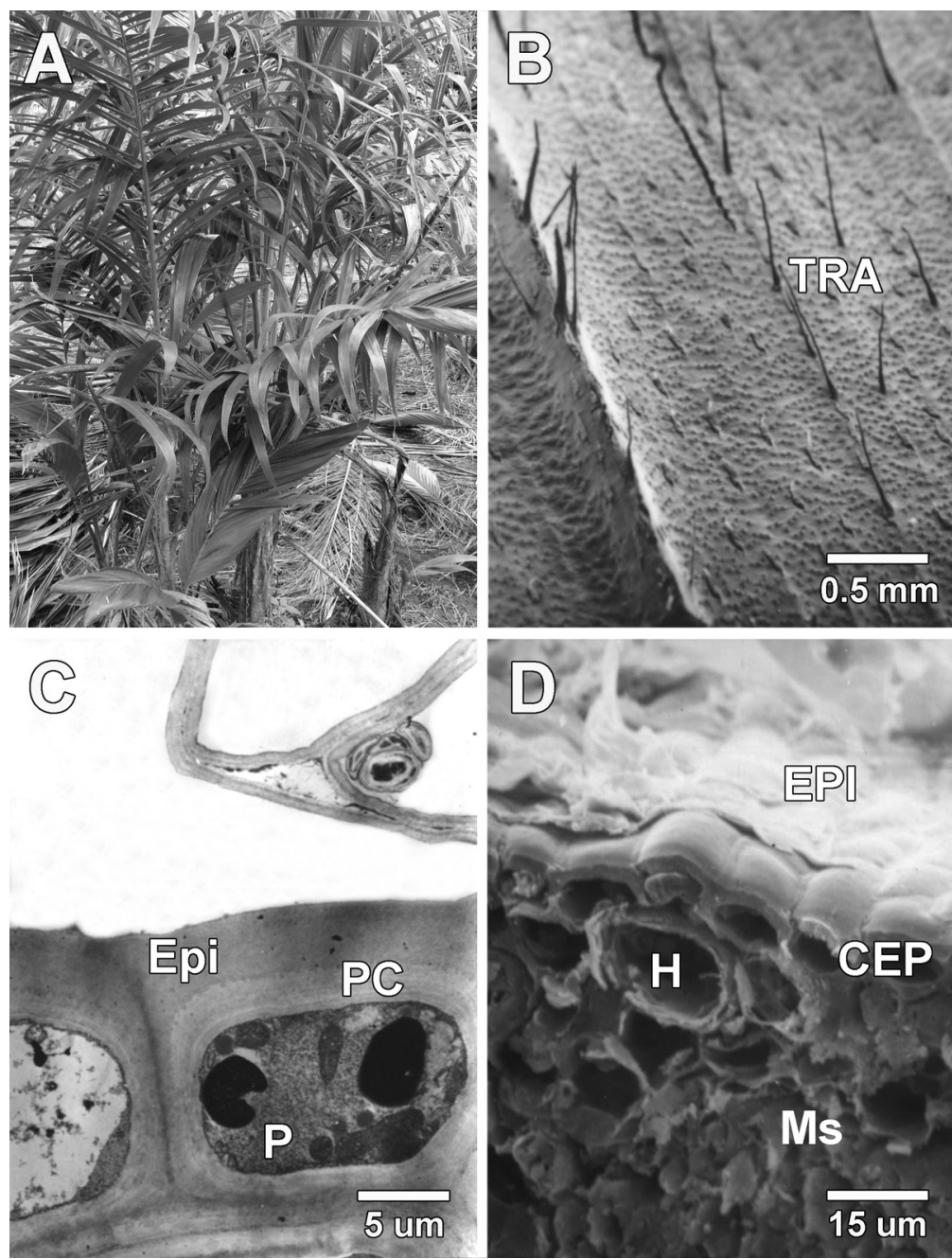

Fig. 1. A) Planta de Bactris gasipaes var. Diamantes-10. B) Superficie abaxial de la hoja mostrando tricomas alargados en la zona costal e intercostal. C) Primera capa de células epidérmicas (superficie adaxial) del foliolo, se observa el contenido de las células epidérmicas. D) Superficie adaxial del foliolo mostrando capa de cera epicuticular, células epidérmicas e hipodérmicas y hacia el interior mesófilo. (TRA: Tricomas alargados espinescentes, EPI: Cera epicuticular, PC: Pared Celular, P: Protoplasto, H: Hipodermis, CEP: Células epidérmicas, Ms: Mesófilo).

Fig. 1. A) Bactris gasipaes var. Diamantes-10. B) Abaxial surface showing trichomes at costal and intercostal sections. C) First epidermal tissue layer (adaxial surface) of leaflet. D) Adaxial surface of leaflet showing epicuticular wax layer, epidermal and hypodermal cells are shown and internal mesophyll. (TRA: Trichomes, EPI: Epicuticular wax, PC: Cell wall, P: Protoplast, H: Hypoderm, CEP: Epidermal tissue, Ms: Mesophyll).

Ambas superficies del foliolo presentaron gran cantidad de cera epicuticular (Fig. 1D). Según el ángulo de visión en que se observó la muestra, las células epidérmicas se observaron como estructuras similares a cordones paralelos a la vena central a $60^{\circ}$ (Fig. 2C) o células con forma sinuosa si no se inclinó el corte (Fig. 3A).

Los foliolos son anfiestomáticos en las áreas intercostales alternando con bandas de células epidérmicas (Fig. 2B). Sin embargo, la superficie abaxial presentó mayor número 

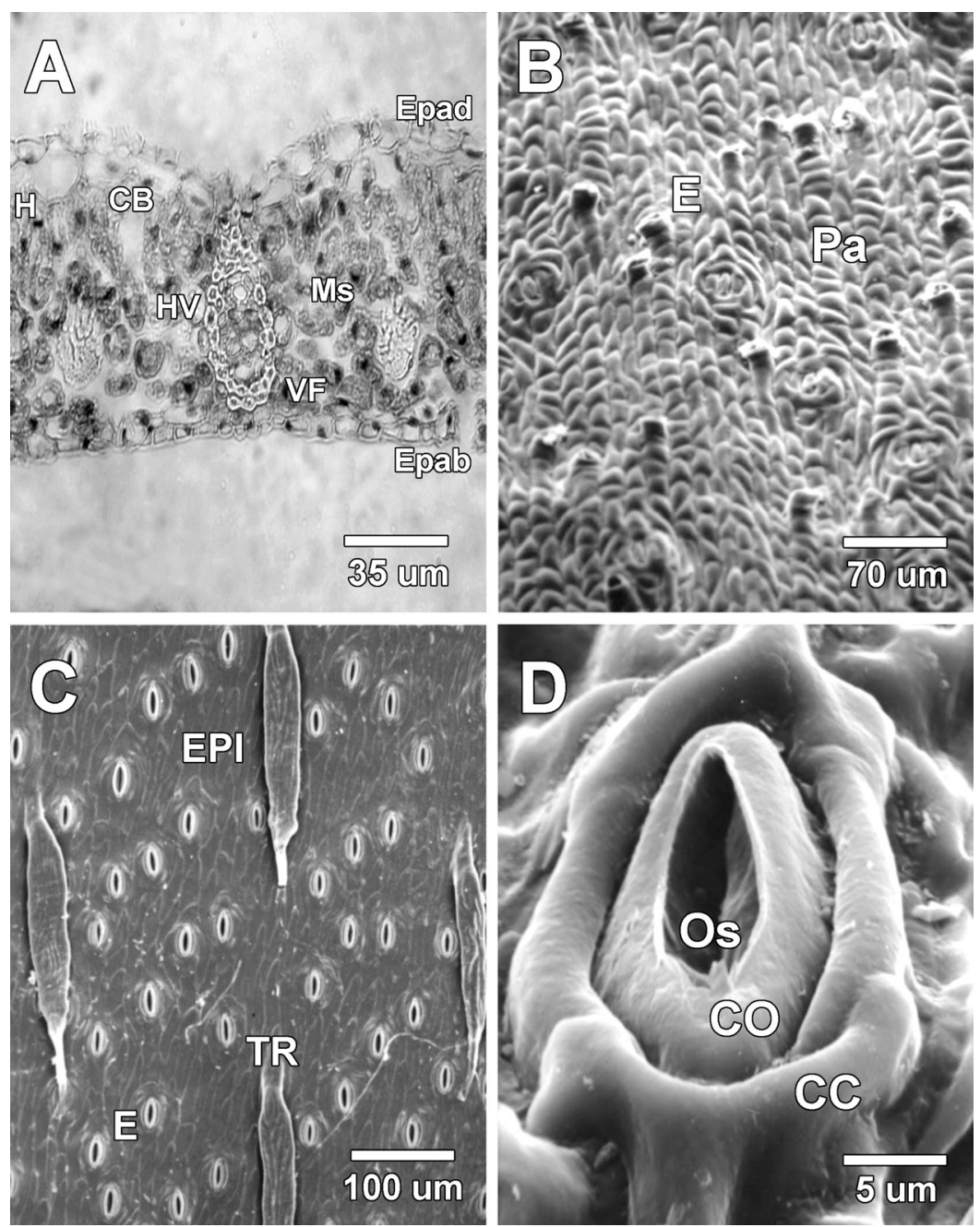

Fig. 2. A) Micrografía de luz del corte transversal del foliolo mostrando las dos capas epidérmicas, varios haces vasculares y los tejidos clorenquimáticos. B) Superficie adaxial del foliolo mostrando las estructura de las células epidérmicas y aproximadamente 15 estomas (en ese campo). C) Superficie abaxial mostrando un tipo de tricoma aparentemente multicelular y 55 estomas en ese campo. D) Estoma, se observa el ostiolo, las células oclusivas y tres células subsidiarias. (Epad: Epidermis adaxial, EPI: Cera epicuticular, Epab: Epidermis abaxial, CB: Célula buliforme, H: Hipodermis, E: Estoma, VF: Vaina de Fibras, HV: Haz vascular, Ms: Mesófilo, Os: Ostiolo, CO: Células oclusivas, CC: Células compañeras).

Fig. 2. A) Light micrograph showing two epidermal layers, vascular vessels and chlorenchyma tissue. B) Leaflet adaxial surface showing epidermal cell structures and approximately 15 stomata (inside photo). C) Trichome on abaxial surface that appears to be multicellular. D) Stomata, ostiole is shown, guard and three subsidiary cells are shown. (Epad: adaxial epidermal cell, EPI: epicuticular wax layer, Epab: abaxial epidermal cell, CB: bulliform cells, H: hypodermis, E: stomata, VF: fibers, HV: vascular bundles, Ms: mesophyll, Os: ostiole, CO: guard cells, CC: subsidiary cells).

de estomas (Fig. 2C). El estoma se encontró conformado por dos células oclusivas, y rodeado por tres células subsidiarias, y por su formación anatómica se les clasifica como tetracíclicos (Fig. 2D).
Con respecto a los tricomas, se encontraron tres tipos en la superficie abaxial. Dos de ellos espinosos donde uno es prominente y recto, únicamente localizado sobre la vena central del foliolo (Fig. 1B), y el segundo también es 

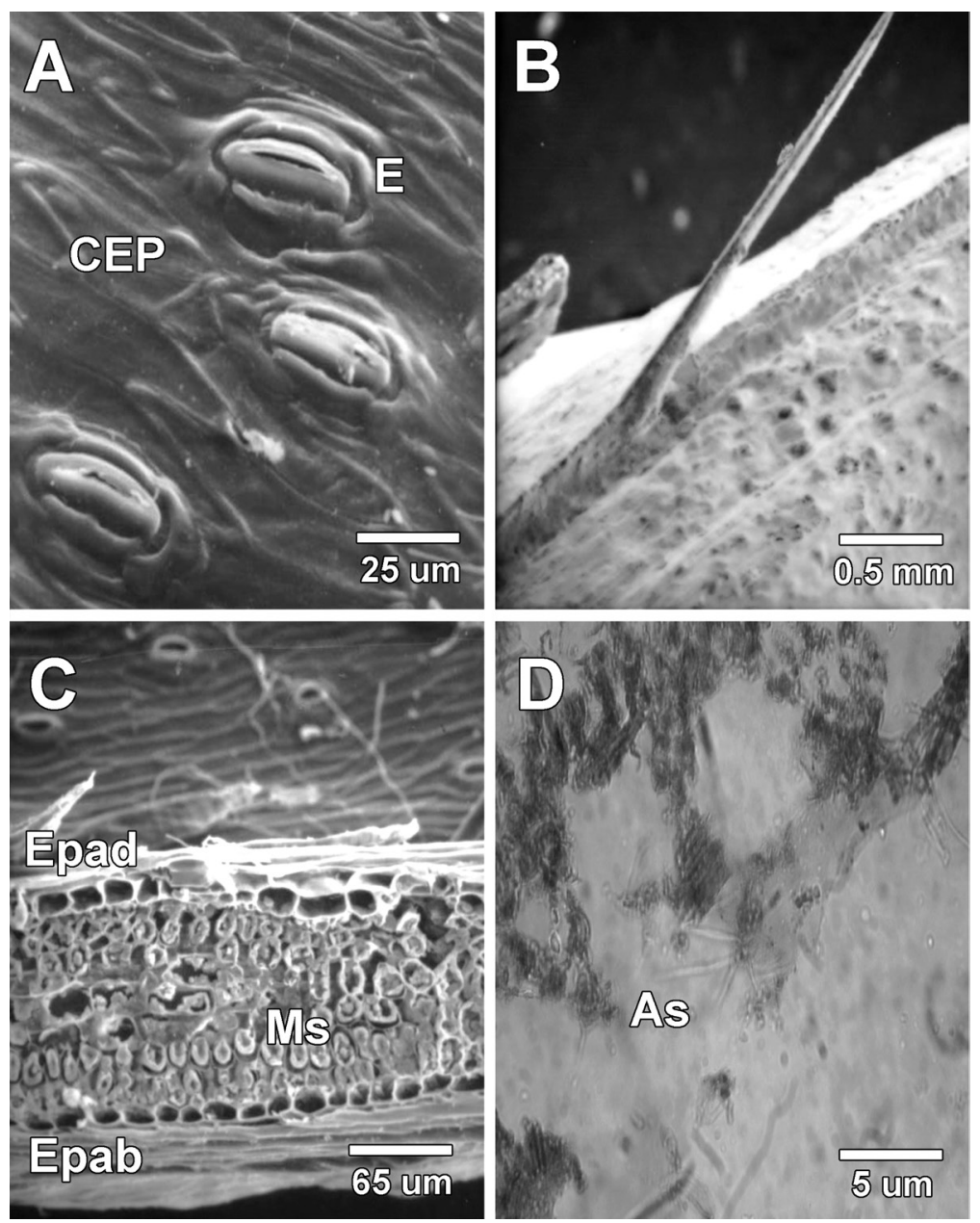

Fig. 3. A) Superficie abaxial de la lámina foliar, se observa estomas y la ornamentación sinuosa de las células epidérmicas. B) Espina sobre la vena central del foliolo. C) Corte transversal de la lámina se observa ambas epidermis, adaxial y abaxial, se observan las células de parénquima. D) Micrografía óptica, presenta una sección de un corte transversal de la lámina y muestra varias astroesclereidas. (Epad: Epidermis adaxial, Epab: Epidermis abaxial, CEP: Cera epicuticular, E: Estoma, Ms: Mesófilo, As: astroesclereida).

Fig. 3. A) Leaflet abaxial surface, stomata and curve ornaments on epidermal cells are shown. B) Thorn on leaflet central vessel. C) Transversal section of leaflet, epidermal layers are shown; internally, parenchymal cells are observed. D) Light micrograph showing cross-section of leaflet with some astrosclereids. (Epad: adaxial epidermis, Epab: abaxial epidermis, CEP: epicuticular wax layer, E: stomata, Ms: mesophyll, As: astroesclereid).

espinoso, pero de menor tamaño, y se observó sobre toda la superficie (Fig. 1B). El tercer tipo de tricoma es más grueso y aparentemente bi o tricelular (multicelular en la base y unicelular en el ápice), y su estructura se presume como bastante débil, ya que colapsó al tratamiento aplicado a las muestras (Fig. 2C).

El parénquima o clorénquima tiene varios estratos no muy bien definidos debido a que la forma y tamaño de las células son muy similares a las de un parénquima esponjoso (Fig. 3C). Dentro de este tejido se pudo observar la presencia de grandes astroescleridas (Fig. 3D). Las células de clorénquima ubicadas en la parte media de la lámina están formadas de células redondeadas de paredes delgadas, dispuestas laxamente y con grandes espacios aéreos (Fig. 4A). Se observa la presencia de haces de 

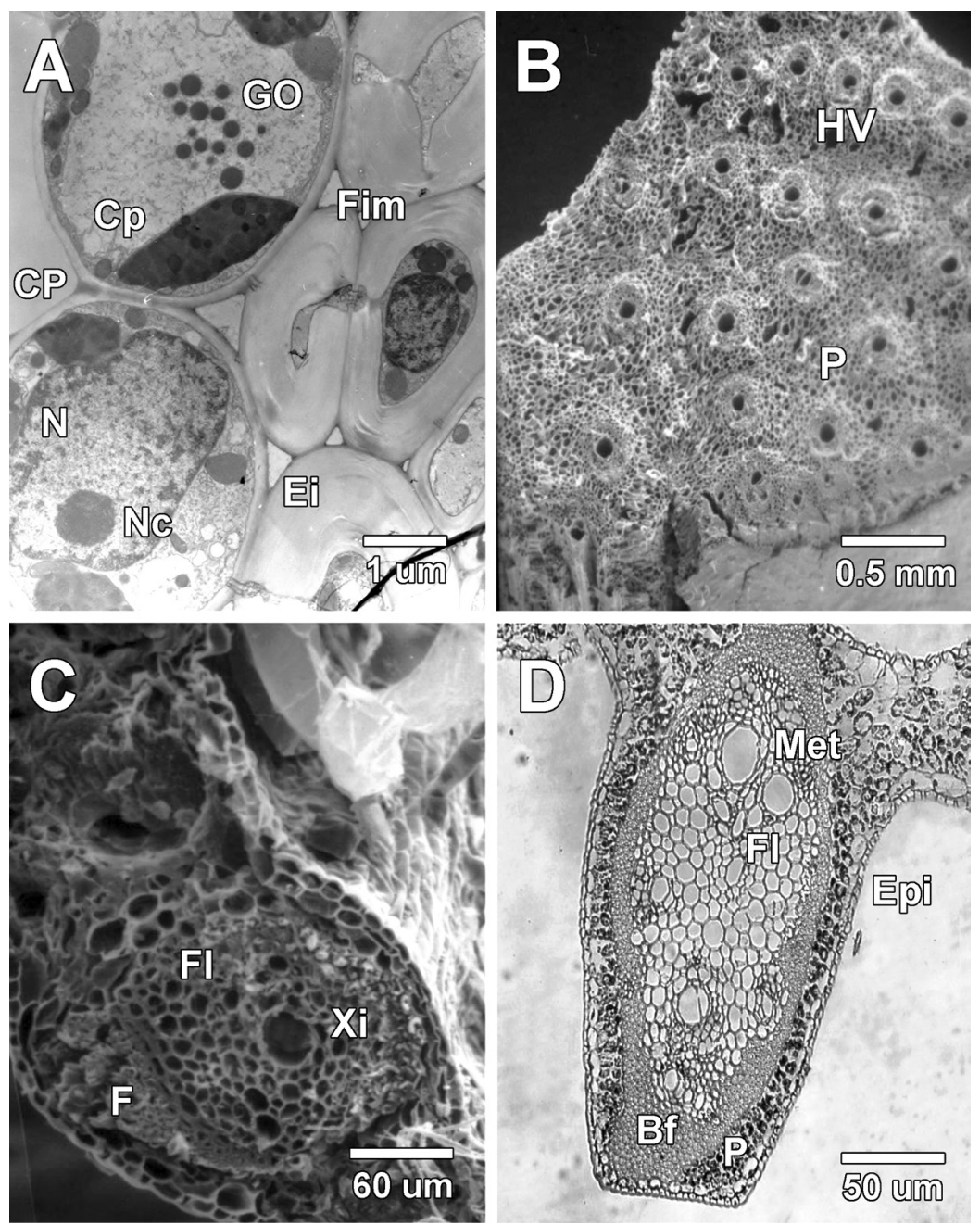

Fig. 4. A) Micrografía de transmisión mostrando una sección de un corte transversal, se notan células del mesófilo con amplios espacios aéreos, junto a estas se observa fibras con protoplasto. B) Corte transversal del raquis (vena central) de la lámina foliar, se observa varios haces vasculares. C) Corte transversal de la vena central del foliolo, se observa vasos del meta y protoxilema, células del floema, la banda de fibras que rodea el haz y las células epidérmicas. D) Micrografía óptica de un corte transversal de la vena central, se observa las mismas estructuras de la foto c, pero en esta se nota claramente la vaina de fibras que rodea el haz. (GO: Glóbulos osmeofílicos, CP: Cloroplasto, Cp: Células de parenquima N: Núcleo, Nc: Nucléolo, Ei: Espacio intercelular, Fim: Fibras inmaduras, Epi: Cera epicuticular. HV: Haz vascular, P: Parenquima, Fl: Floema, Met: Metaxilema, F: Fibras, Xi: Xilema, Fl: Floema, CC: Células compañeras).

Fig. 4. A) TEM micrograph showing a transversal section, where mesophyll with air spaces is observed, next to protoplast fibers. B) Cross-section of petiolules of the leaflet, some vascular vessels are shown. C) Transversal section of main vessel in leaflet, meta and protoxylem structures are shown, also phloem cells, fiber groups surrounding the vessel and epidermal cells. D) Light micrograph showing cross-section of main vessel, with evident fiber groups surrounding the vessel. (GO:gobule, CP: chloroplastid, Cp: parenchyma cell, N: nucleus, Nc: nucleolus, Ei:intercellular space, Fim: inmature fibers, Epi: epicuticular wax layer. HV: vascular bundles, P: parenchyma, Fl: phloem, Met: metaxylem, F: fibers, Xi: xylem, CC: companion cell). 
fibras incluidas dentro del tejido parenquimatoso a modo de grupos de células con pared engrosada, lignificada y compacta (Fig. 1D y Fig. 2A). También se observó la presencia de células buliformes (Fig. 4D).

La vena central o raquis de la lámina presenta varios haces vasculares, algunos de ellos dispuestos en forma continua (Fig. 4B, Fig. 4C y Fig. 4D); estos se encuentran rodeados de una vaina de tejido esclerotizado, compuesto de gran cantidad de fibras de paredes muy gruesas y lumen muy estrecho (Fig. 5A). En algunas de estas fibras se presentan protoplastos vivos (Fig. 4A) y son de forma alargada y aguzada en
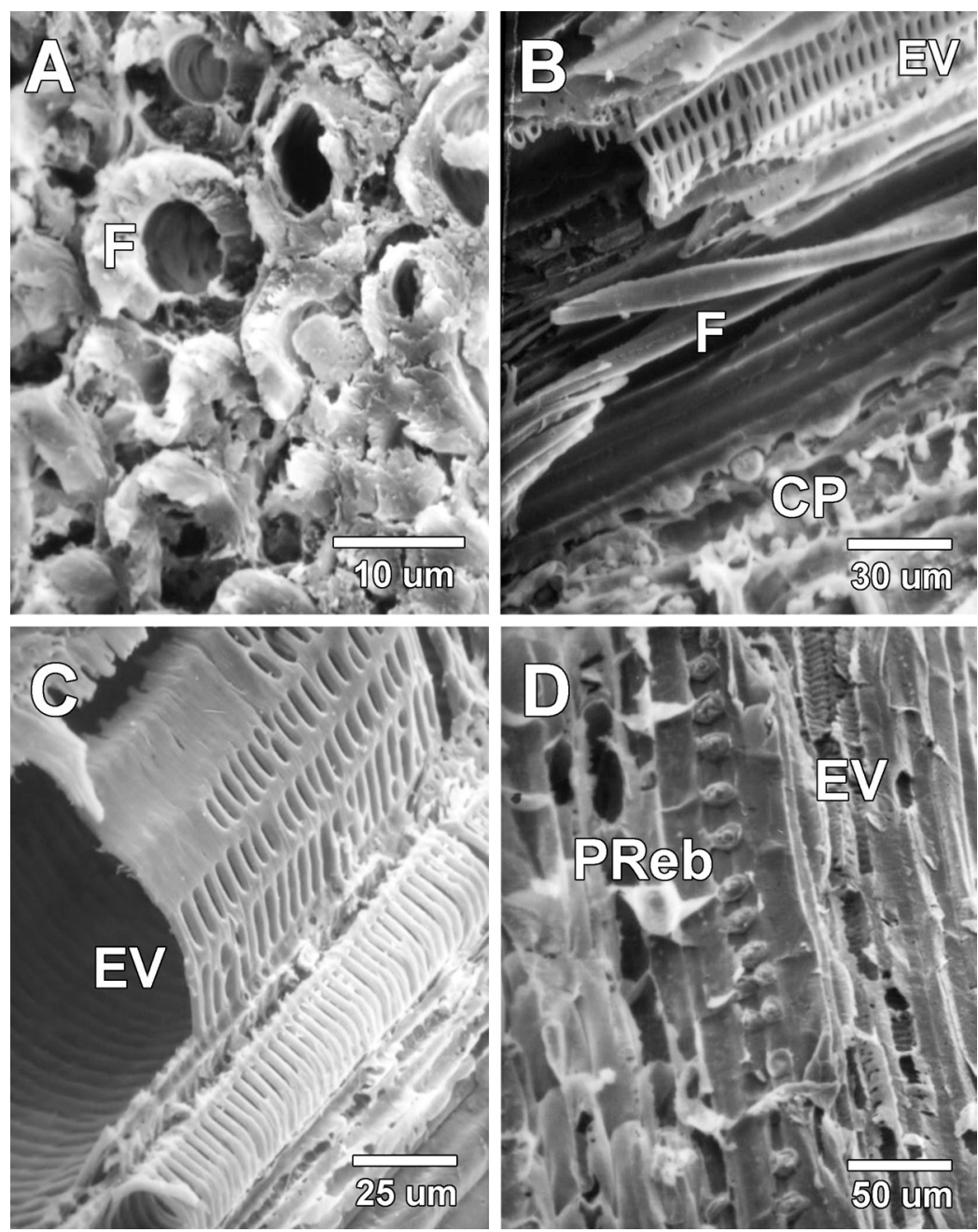

Fig. 5. A) Vaina de tejido esclerenquimático (fibras) que rodean el haz vascular. B) Fibra con extremo aguzado junto a un vaso de metaxilema con paredes con ornamentaciones escalariformes. También se observa algunas células de forma más regular que podrían corresponder a células de parénquima. C) Xilema. Un vaso de metaxilema y protoxilema con paredes con ornamentación escalariforme. D) Puntuaciones rebordeadas de una traqueida. (PReb: Puntuaciones rebordeadas, F: Fibras, EV: Elementos de los vasos, CP: Célula de Parénquima).

Fig. 5. A) Sclerenchymatic tissue (fiber) surrounding vascular vessel. B) Pointed fiber next to metaxylem vessel with scalariform ornaments on the wall. Also, apparent parenchymatic cells with a more regular shape are shown. C) Xylem. Metaxylem and protoxylem vessels with scalariform ornaments on the wall. D) Branched plasmodesma in tracheid. (PReb: boarded thickening, F: fibers, EV: vessel members, CP: parenchymatic cell). 
los extremos, y no se observó ramificaciones ni septos (Fig. 5B). Todas las venas menores presentan la misma anatomía.

En el xilema se observó varios vasos de metaxilema y protoxilema, ambos con ornamentaciones escalariformes en sus paredes laterales (Fig. 5C) y puntuaciones rebordeadas de sus paredes (Fig. 5D y Fig. 6A). La placa perforada que separa los elementos de los vasos es de estructura escalariforme (Fig. 6B). El
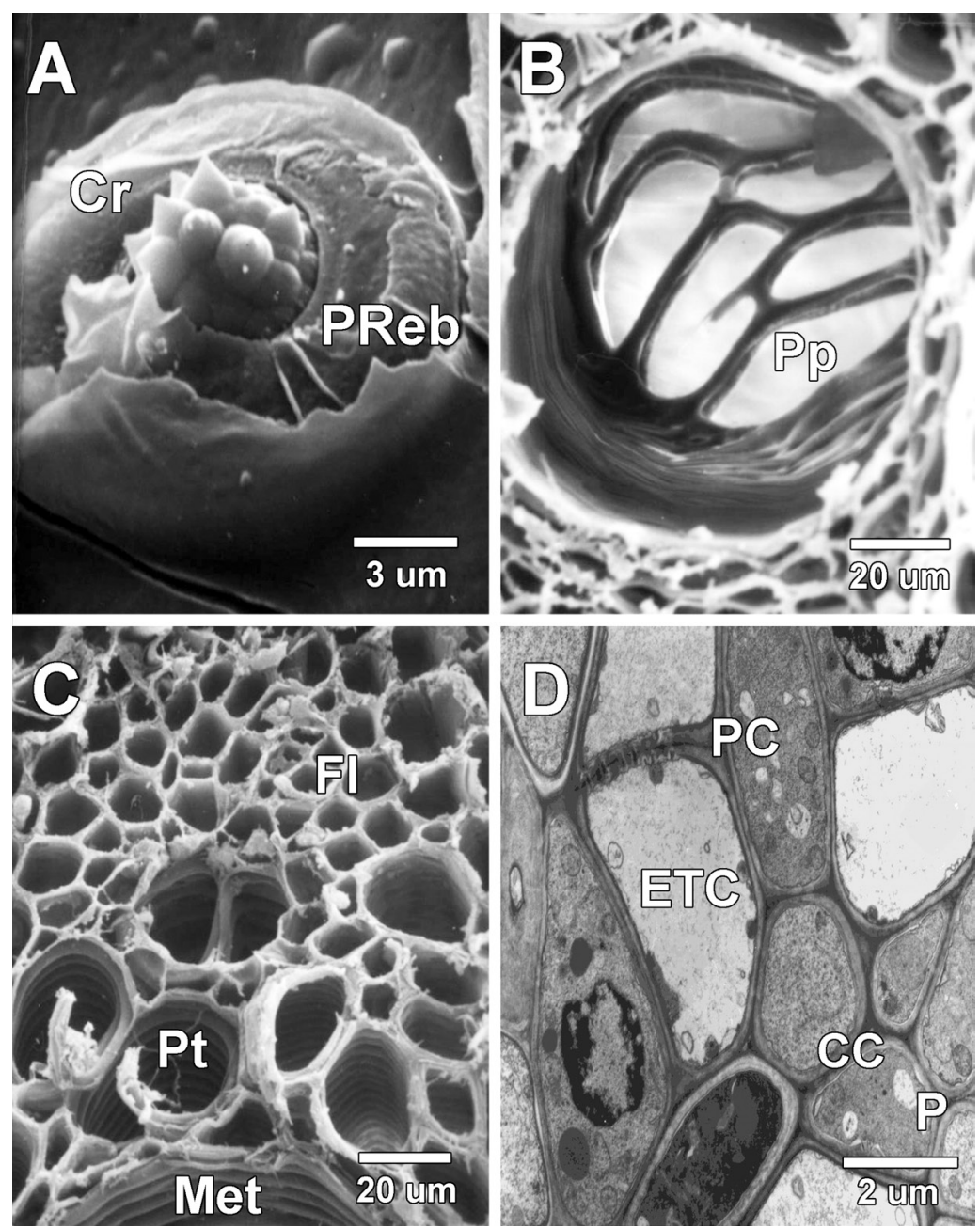

Fig. 6. A) Puntuación rebordeada, se observa en el interior un grupo de cristales. B) Placa perforada escalariforme de un elemento de los vasos del metaxilema. C) Se observa el floema en la parte superior de los vasos del protoxilema, se observa células de los elementos cribosos con la respectiva célula compañera y se nota también células de parénquima. D) Micrografía electrónica de transmisión mostrando el floema de un haz vascular, se nota las células compañeras y varios elementos cribosos, entre dos elementos cribosos se observa la placa cribosa. (Fl: Floema, Cr: Cristales, PReb: Puntuación rebordeada, Pp: Placa perforada, Pt: Protoxilema, Met: Metaxilema, P: Parenquima, ETC: Elementos de los tubos cribosos, PC: Placa cribosa, CC: Células compañeras).

Fig. 6. A) Branched plasmodesma, an accumulation of crystals is observed. B) Scalariform perforation plate of vessel elements in metaxylem. C) Phloem in upper side of protoxylem vessel, sieve tube elements and companion cell are shown, also parenchyma cells are noted. D) TEM micrograph showing vascular vessel of phloem, companion cells and sieve tube elements; between two sieve elements, the sieve plate is shown. (Fl: phloem, Cr: crystals, PReb: boarded thickening, Pp: perforation plate, Pt: protoxylem, Met: metaxylem, P: parenchyma, ETC: sieve elements, PC: sieve area, CC: companion cell). 


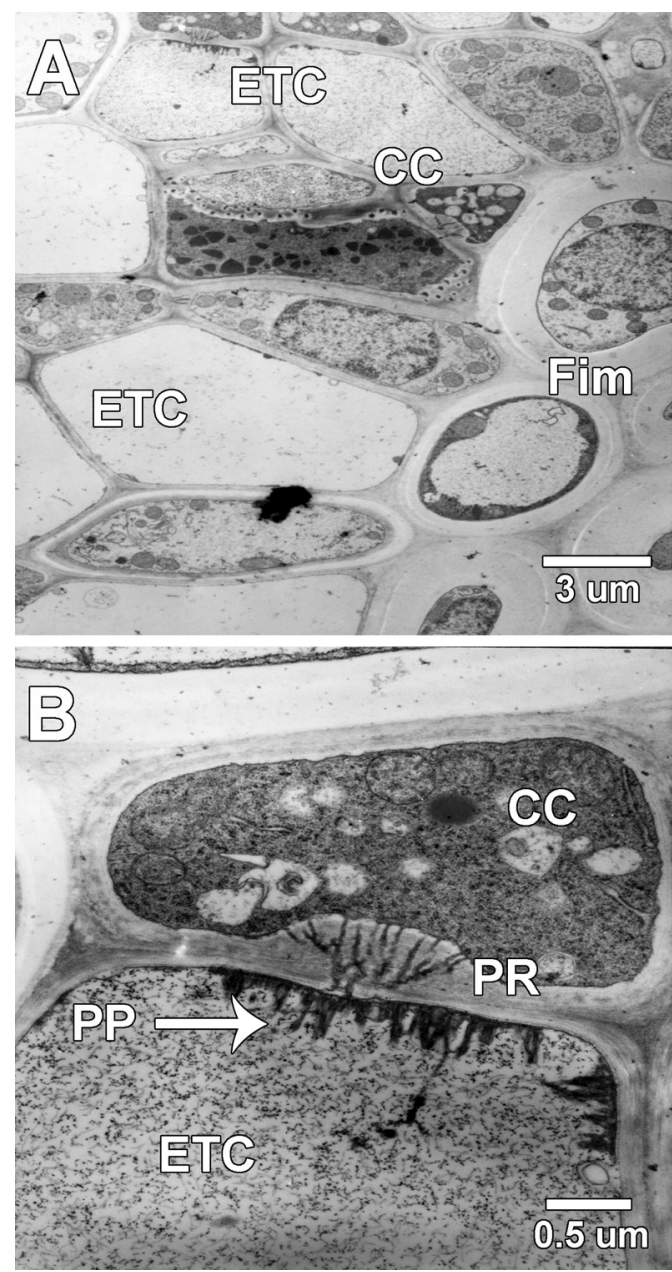

Fig. 7. Floema. A) Se observa los diferentes componentes de este tejido, varios elementos de los tubos cribosos algunos con filamentos de P-proteína. Se nota algunos elementos de los tubos cribosos inmaduros, células compañeras con campos de puntuaciones y también se observa algunas fibras con protoplastos. B) Elemento criboso junto a la célula compañera, se observa los plasmodesmos ramificados entre ellos y en la pared del elemento criboso se nota filamentos de P-proteína. (Fim: Fibras inmaduras, PP: Proteína P, PR: Plasmodesmos ramificados, ETC: Elementos de los tubos cribosos, CC: Células compañeras).

Fig. 7. Phloem. A) It is noted the different structures that form this tissue, sieve tube elements are shown, some of them with P-protein fibers. Also, there are immature sieve tube elements, companion cells with plasmodesmata and some protoplast fibers. B) Sieve tube element next to companion cell; between sieve elements cross-lined plasmodesmata and fibers of P-protein are shown. (Fim: immature fibers, PP: P- protein, PR: crosslined plasmodesmata, ETC: sieve tube elements, CC: companion cells). floema se encuentra hacia la superficie adaxial de la vena y en corte transversal se observan las células cribosas con las células compañeras rodeadas de células de parénquima (Fig. 6C). En micrografías electrónicas de transmisión (Fig. 6D y Fig. 7A), se observó el detalle interno de las células del floema, se observan células compañeras, elementos de los tubos cribosos, fibras y parénquima. Se visualizaron células compañeras con plasmodesmatas ramificados unidos a un elemento de los tubos cribosos, el cual en su interior presenta filamentos electrón-densos que corresponden a cuerpos de proteína (P-proteína) (Fig. 7B) (Cronshaw \& Esau, 1968).

\section{DISCUSIÓN}

Basado en los resultados de la hoja de $B$. gasipaes var. Diamantes-10, no se puede argumentar que esta variedad presente un número significativo de características morfológicas distintas a las de otras variedades. La diferencia la conforma la presencia de un número mínimo de espinas en los foliolos, que la favorece como variedad de cultivo intensivo y facilita la industrialización de la planta (Mora-Urpí \& Gainza, 1999).

En lo que respecta a la venación paralela, según Tomlinson (1990) y Tomlinson et al., (2011) es una característica que la familia Arecaceae comparte con el resto de las monocotiledóneas (Esau, 1959; Fahn, 1982; Esau, 2006; Chaimsohn et al., 2008; Tomlinson et al., 2011; Flores-Vindas, 2013). La presencia de gran cantidad de cera epicuticular también ha sido repostada en otros estudios para esta especie (Batagin-Piotto et al., 2012), y también para otras especies, la presencia de cera epicuticular se encuentra relacionada a la regulación de la transpiración y la pérdida pasiva de agua (Taiz \& Zeiger, 2010). La anatomía de las células epidérmicas descritas en los foliolos de esta variedad, coincide con la reportada por Tomlinson (1990) y Tomlinson et al. (2011) para otras especies de Bactris sp. Comparado con los resultados de Chaimsohn et al. (2008) y Batagin-Piotto et al. (2012) no existe 
diferencia con otras variedades de $B$. gasipaes en cuanto a las características de las células epidérmicas y la disposición uniserial en ambas superficies foliares.

Los estomas de la variedad Diamantes-10 son tetracíclicos y son comunes en la familia Arecaceae (Pérez \& Rebollar, 2003; Passos \& Mendoca, 2006; Silva \& Potiguara, 2008, Tomlinson et al., 2011, Batagin-Piotto et al., 2012). En esta variedad se pudo observar la presencia de una hipodermis de células agrandadas y células buliformes que ya habían sido reportadas para B. gasiapes por Chaimsohn et al. (2008). Tomlinson (1990), Tomlinson et al. (2011) y Chaimsohn et al. (2008) mencionan que la presencia de una hipodermis le permite a las palmas desarrollarse en ambientes libres de sombra y aprovechar de manera eficaz la radiación.

En Bactris gasipaes var Diamantes 10, las células del clorénquima presentan una anatomía similar a la de otras palmas (Chaimsohn et al., 2008; Tomlinson et al., 2011). En el clorénquima de la palma del género Sabal los espacios intercelulares son muy reducidos (Pérez \& Rebollar, 2003), mientras en Diamantes-10 los espacios intercelulares son más grandes, característica que le permite mayor reserva de aire $\left(\mathrm{CO}_{2}, \mathrm{O}_{2}\right)$ (Paniagua et al., 2000; Chaimsohn et al., 2008). Esto podría estar relacionado a una mayor capacidad fotosintética (Taiz \& Zeiger 2010).

Phoenix datylifera y Borassus flabellifer presentan la vaina de fibras esclerenquimáticas que rodea el haz vascular como la observada en esta variedad, pero Cocos sp. y Eugeissona sp., no la presentan, aunque estos dos últimos géneros si comparten con la variedad Diamantes-10 la presencia de astroesclereidas en los tejidos colenquimáticos (Tomlinson, 1990; Chaimsohn et al., 2008). En Bactris y géneros relacionados, las fibras son estrechas y el lumen celular casi se ocluye, esto fue claramente observado en este estudio y es citado en los estudios de Tomlinson (1990) Tomlinson et al., (2011) y de Chaimsohn et al. (2008). Es importante mencionar que respecto a los datos obtenidos por Chaimsohn et al. (2008), las imágenes obtenidas de la variedad Diamantes-10 sugieren que los haces de fibras son de mayor grosor.

Las características anatómicas del xilema y el floema coinciden con las descritas por Tomlinson (1990) para las especies de palma Mauritia sp., Rhapis excelsa, Calamus sp, Calospatha sp., Ceratolobus sp., Daemonorops sp., Cocos sp. y por Pérez \& Rebollar (2003) para las especies $S$. mexicana, S. mauritiiformis y $S$. yapa. Asimismo, se evidencia mediante la anatomía observada de los haces vasculares que el mecanismo fotosintético es $\mathrm{C}_{3}$, lo cual ya había sido reportado por Chaimsohn et al. (2008). En este sentido, haces vasculares compuestos por un vaso agrandado de metaxilema con vasos menores de protoxilema, acompañados de floema y rodeado de parénquima con un anillo de células esclerenquimatosas, es la disposición típica de un haz vascular de una planta $\mathrm{C}_{3}$ (Lambers, Pons, \& Chapin, 2008). Los cuerpos de P-proteína observada en los elementos de los tubos cribosos es una proteína característica de este tipo de células, en este caso se observó el tipo fibrilar y no el tubular (Cronshaw \& Esau, 1968; Algan \& Bakar, 2002).

Según autores como Parthasarathy \& Tomlinson (1967), Parthasarathy (1968) y Tomlinson (1990), la estructura de los haces vasculares y la distribución de estos en la lámina y pecíolo, tiene valor diagnóstico para distinguir los diferentes taxones de palmas. Asimismo, la presencia de haces de fibras ocluidas dentro del parénquima es un carácter común entre las palmas, pero la disposición es distintiva entre las diferentes especies (Tomlinson, 1961; Batagin-Piotto et al., 2012). Además, la estructura histológica de la lámina refleja las características de resistencia y flexibilidad necesarias ante el estrés mecánico ocasionado por vientos o lluvias (Esau, 1959; Mora-Urpí, 1993).

Los estudios de este tipo, aportan nueva información para el entendimiento de aspectos fundamentales de la fisiología de la planta, como lo son el transporte de sustancias, absorción, almacenamiento, fotoasimilación y también ayudan a comprender mejor el fenómeno 
de resistencia al ataque de plagas y el comportamiento de la planta cuando se ve afectada por una enfermedad (Tomlinson, 1990). Con base en la anatomía de los foliolos de $B$. gasipaes var. Diamantes-10, no se encontraron diferencias anatómicas de importancia respecto a los datos informados para otras variedades, lo que sugiere que las diferencias en cuanto a la producción se relacionan principalmente con aspectos fisiológicos.

\section{AGRADECIMIENTOS}

Este trabajo está dedicado a Jorge Mora Urpí quien hoy ya no se encuentra entre nosotros, pero nos dejó grandes enseñanzas. Se agradece a Doris Fernández por su colaboración en el proceso para microscopía de luz, a Frank Jiménez Guevara por su participación en la recolecta de muestras, a Rolando Moreira Soto por la revisión del idioma inglés y a la Vicerrectoría de Investigación de la Universidad de Costa Rica por el aporte económico a través de los proyectos $\mathrm{N}^{\mathrm{o}} 810-\mathrm{A} 7-133$ y el $\mathrm{N}^{\circ} 810-\mathrm{B} 0-603$ y al Centro de Investigación en Estructuras Microscópicas (CIEMic) por permitir el desarrollo de este trabajo.

\section{RESUMEN}

Bactris gasipaes se cultiva ampliamente para el aprovechamiento del palmito y el consumo de los frutos En este trabajo se realizó una descripción de las características micro morfológicas de los foliolos de plantas adultas de la variedad sin espinas Diamantes-10 de B. gasipaes, recolectadas en la Estación Experimental Diamantes en Guápiles, Costa Rica. Se utilizó microscopía de luz, electrónica de barrido y de transmisión. Para el estudio se recolectaron 25 foliolos y se evidenció abundante cera epicuticular en la superficie adaxial y abaxial. La epidermis está compuesta de células isodiamétricas y las células de la hipodermis tienen forma rectangular y son de mayor tamaño que las de la epidermis, también se observaron células buliformes. Los foliolos son anfiestomáticos en las áreas intercostales y alternan con bandas de células epidérmicas. El mayor número de estomas se encuentra en la superficie abaxial. Estos foliolos presentan tres tipos de tricomas. El parénquima presenta varios estratos no muy bien definidos con presencia de astroesclereidas. También se observan haces de fibras entre el parénquima que forman grupos de células muy compactas. La vena central presenta varios haces vasculares, algunos dispuestos de forma continua y todos ellos se encuentran rodeados de una vaina de tejido esclerotizado, algunas de estas fibras presentaron protoplastos vivos. Todas las venas menores presentan la misma anatomía de los haces vasculares de la vena central. Los vasos del protoxilema y metaxilema tienen paredes laterales con ornamentaciones escalariformes. El floema se ubica hacia la superficie adaxial de la vena y en el corte se observaron las células cribosas y células compañeras rodeadas de células de parénquima y fibras. Las células compañeras presentaron plasmodesmatas ramificados unidos a un elemento criboso y en ellos se evidenció cuerpos de proteína, llamada proteína-P. La diferencia principal en la anatomía de los foliolos de la var. Diamantes-10 radica en la ausencia de espinas, pero en el resto de la morfología no parece presentar cambios morfológicos con el resto de las variedades de B. gasipaes $\mathrm{K}$.

Palabras clave: ultraestructura, foliolos, palmito, pejibaye, variedad.

\section{REFERENCIAS}

Algan, G. \& Bakar, B. N. (2002). P-Protein structure in functional an non-functional secondary phloem in Armeniaca vulgaris Lam (Rosaceae). Turkish Journal of Botany, 26, 213-217.

Arroyo, C., \& Mora-Urpí, J. (2002). Producción comparativa de palmito entre cuatro variedades de pejibaye (Bactris gasipaes Kunt). Agronomía Mesoamericana, 13, 135-140.

Batagin-Piotto, K. D., Vieira De Almeida, C., Piotto, F. A., \& De Almeida, M. (2012). Anatomical analysis of peach palm (Bactris gasipaes) leaves cultivated in vitro, ex vitro and in vivo. Brazilian Jounal of Botany, 35(1), 71-78.

Bogantes, A., Agüero, R., \& Mora-Urpí, J. (2004). Palmito de pejibaye (Bactris gasipaes K.): Distancias de siembra y manejo de malezas. Agronomía Mesoamericana, 15, 185-192.

Bozzola, J. J. \& Russell, L. D. (1992). Electron Microscopy. Principles and Techniques for Biologists. Sudbury, Massachusetts: Jones and Bartlett Publishers, Inc.

Chaimsohn, F. P., Montiel, M., Villalobos E., \& MoraUrpí, J. (2008). Anatomía micrográfica del foliolo de la palma neotropical Bactris gasipaes (Arecaceae). Revista de Biología Tropical, 56, 951-959.

Clement, C. R., \& Mora-Urpí, J. (1983). Leaf morphology of the pejibaye palm (Bactris gasipaes H. B. K.). Revista de Biología Tropical, 31(1), 103-112.

Clement, C. R., Mora-Urpí, J., \& Costa, S. D. (1985). Estimación del área foliar de la palma de pejibaye 
(Bactris gasipaes H. B. K.). Revista de Biología Tropical, 33(2), 99-105.

Cronshaw, J., \& Esau, K. (1968). P Protein in the Phoem of Cucurbita. II. The P Protein of Mature Sieve Elements. Journal of Cell Biology, 38, 292-303.

Esau, K. (1959). Anatomía Vegetal. Barcelona: Ediciones Omega, S. A.

Esau, K. (2006). Esau's Plant Anatomy. Meristmas, Cells, and Tissues of the Plant Body: Their Structure, Function, and Development. Nueva Jersey: John Wiley and Sons Inc.

Fahn, A. (1982). Plant Anatomy. New York: Pergamon Press Inc.

Ferreira, E. (1999). The phylogeny of pupunha (Bactris gasipaes Kunth, Palmae) and allied species. Memoirs of the New York Botanical Garden, 83, 225-236.

Flores-Vindas, E. (2013). La planta: estructura y función. Cartago: Editorial Tecnológica de Costa Rica.

Horn, J. W., Fisher, J. B., Tomlinson, P. B., Lewis, C. E., \& Laubengayer, K. (2009) Evolution of lamina anatomy in the palm family (Arecaceae). American Journal of Botany, 96(8), 1462-1486.

Karnovsky, M. J. (1965). A formaldehyde-glutarandehyde fixative of high osmolarity for use in electron microscopy. Journal of Cell Biology, 27, 137-138.

Lambers, H., Pons, T. J., \& Chapin, F. S. (2008). Plant physiological ecology. Nueva York: Springer.

Magellan, T. M., Tomlinson, P. B., \& Huggett, B. A. (2015). Stem anatomy in the spiny American palm Bactris (Arecaceae-Bactridinae). Hoehnea, 42(3), 567-579.

Mattos-Silva, L. (1992). Diferenciación taxonómica de diez razas de Pejibaye Cultivado (Bactris (Guilielma) gasipaes $K$.) y su relación con otras especies de Bactris. Tesis de Ingeniería Agrícola, Universidad de Costa Rica.

Mora-Urpí, J. \& Gainza, J. (1999). Palmito de pejibaye (Bactris gasipaes Kunth): Su cultivo e industrialización. San José: Editorial de la Universidad de Costa Rica.

Mora-Urpí, J. (1993). Diversidad genética del pejibaye: II. Origen y Evolución. IV Congreso Internacional sobre Biología, Agronomía e Industrialización del Pijuayo. Iquitos. Costa Rica: Editorial de la Universidad de Costa Rica.
Mora-Urpí, J., Arroyo-Oquendo, C., Mexzón-Vargas, R., \& Bogantes-Arias, A. (2008). Diseminación de la "Bacteriosis del palmito" de pejibaye (Bactris gasipaes Kunth). Agronomía Mesoamericana, 19(2), 155-166.

Mora-Urpí, J., Weber, J. C., \& Clement, C. R. (1997). Peach Palm Bactris gasipaes Kunth. Promoting the conservation and use of underutilized and neglected crops 20. Roma: Institute of Plant Genetics and Crop Plant Research.

Paniagua, R., Nistal, M., Sesma, M., Alvarez-Uría, M., Anadón, R., Fraile, B., Sáez, F., \& González, M. P. (2000). Citología e histología animal $y$ vegetal. Madrid: Mc.Graw-Hill Interamericana de España, S. A.

Parthasarathy, M., \& Tomlinson, P. B. (1967). Anatomical features of metaphloem in Sabal, Cocos and two other palms. American Journal of Botany, 54, 1143-1151.

Parthasarathy, M. (1968). Observations on metaphloem in vegetative parts of palms. American Journal of Botany, 55, 1140-1168.

Passos, M. A., \& Mendonca, M. S. (2006). Epiderme dos segmentos foliares de Mauritia flexuosa L. F. (Arecaceae) em tres fases de desenvolvimiento. Acta Amazonica, 36, 431-436.

Pérez, M. \& Rebollar, S. (2003). Anatomía y usos de las hojas maduras de tres especies de Sabal (Arecaceae) de la Península de Yucatán, México. Revista de Biología Tropical, 51(2), 333-344.

Robards, W. \& Wilson, A. J. (1993). Procedures in Electron Microscopy. York: John Wiley \& Sons.

Silva, R. J. F., \& Potiguara, R. C. V. (2008). Aplicacoes taxonómicas da anatomía foliar de espécies amazónicas de Oenocarpus Mart. (Arecaceae). Acta Botanica Brasilica, 22(4), 999-1014.

Taiz, L. \& Zeiger, E. 2010. Fisiología vegetal. Porto Allegre: Artmed.

Tomlinson, P. B. (1990). The structural Biology of Palms. New York: Clarendon Press.

Tomlinson, P. B., Horn, J. W., \& Fisher, J. B. (2011). The anatomy of palms (Arecaceae-Palmae). Oxford: Oxford University Press.

Valera, R., Maciel, N., Sanabria-Chópite, M. E., \& Mendoza, A. (2012). Anatomía de la lámina foliar de plántulas de seis especies de palmeras (Arecaceae) del bosque húmedo de Río Claro, estado Lara, Venezuela. Revista Cientifica UDO Agrícola, 12(4), 779-794. 
